\title{
Aprendizagem escolar de estudantes da educação de jovens e adultos
}

The School learning in youth and adult education

\author{
Susana Gakyia Caliatto \\ Universidade do Vale do Sapucaí \\ Selma de Cássia Martinelli \\ Universidade Estadual de Campinas
}

\section{Resumo}

$\bigcirc$ presente artigo apresenta resultados de uma pesquisa que destaca singularidades do público da Educação de Jovens e Adultos (EJA), em sua relação com o processo de aprendizagem escolar e com a autoeficácia acadêmica. Participaram do estudo 108 estudantes, de ambos os sexos, com idades entre 15 e 62 anos, do Estado de São Paulo. $\bigcirc$ instrumento utilizado foi um questionário que versava sobre a trajetória escolar, e as respostas também foram analisadas à luz da teoria da autoeficácia acadêmica que pode ser relacionada ao esforço para realizar tarefas escolares, organizar estratégias para o estudo, estabelecer metas e persistir nas adversidades. A pesquisa levantou dificuldades e sucessos dos estudantes que podem revelar aspectos de um status próprio desse segmento de ensino, além de apontar para implicações educacionais e novas perspectivas de estudos.

Palavras-chave: Educação de Jovens e Adultos. Psicologia cognitiva. Aprendizagem.

\section{Abstract}

The present article presents the results of a research that points out public's singularity in Young People and Adults' Education (EJA), in its relation with the school learning process and with the academic self-efficacy. A hundred eight students participated of the study, both male and female, with ages between 15 and 62, from São Paulo State. The instrument used was a questionnaire that ran upon school trajectory and the answers were also analyzed by the light of the theory of academic self-efficacy which can be related to the efforts to carry out school tasks, organize strategies to the study, to establish goals and persist in adversities. The research surveyed students' difficulties and successes that can reveal aspects of an own status of this teaching continuation, besides pointing at educational implications and studies' new perspectives.

Keywords: Young People and Adults' Education. Cognitive psychology. Learning. 
A Educação de Jovens e Adultos (EJA) é uma modalidade de ensino que compõe a educação básica nacional. Tem a finalidade de atender indivíduos que não completaram o ensino fundamental e o médio em idade comum e, necessitam completar a escolarização em curto espaço de tempo. Segundo - Ministério da Educação - MEC (BRASIL, 2001; 2006), os cursos de EJA, além de abreviarem o tempo que se gastaria num curso convencional, oferecer certificação aos alunos que abandonaram a vida escolar na idade própria, e retomam os estudos mais tarde, devem fornecer recursos para aquisição das aprendizagens escolares e desenvolver habilidades de aprendizagem que vão permanecer ao longo da vida. Devido à especificidade dessa modalidade de educação e de seu público, esse segmento de ensino tem proporcionado o debate de ideias em pesquisas que apontam para a necessidade de inclusão de pessoas que podem estar marginalizadas na sociedade, devido à condição de serem pouco escolarizadas, e de compreender as características próprias de um público que retoma os estudos em idade adulta. (OLIVEIRA, 2010).

Stromquist (2001) e Oliveira (2010), além de apontarem para a necessidade de acesso educacional dos jovens e adultos que ainda não completaram a educação básica, também defendem que a alfabetização é uma 110 capacidade básica que reflete no desenvolvimento do indivíduo e em seu bom desempenho escolar, na realização pessoal, no autodirecionamento e participação na sociedade. Assim, observa-se que tanto a alfabetização quanto a aquisição de conhecimentos, considerados do mundo letrado, se efetivam por meio de práticas culturais ou em situações e experiências da vida cotidiana e tornam-se fundamentais no processo de inserção social.

O estudo de Costa (2003) mostrou que a exclusão de cidadãos brasileiros de práticas socioculturais acontece pela falta de práticas discursivas, faladas ou escritas, e por pouca instrução escolar. Corroboram essa afirmação os dados fornecidos pelo Indicador Nacional de Alfabetismo Funcional (INAF, 2009) que revela que, apenas, 15\% dos brasileiros entre 15 e 64 anos, que cursam ou cursaram o ensino fundamental até a oitava série, podem ser considerados alfabetizados. Sobre esse perfil, a pesquisa demonstrou que as pessoas com baixa renda tiveram menor acesso à escolarização e, consequentemente, menor acesso à informação e à cultura formal como o recebimento de cartas, a frequência a cinemas e teatros, além de outros eventos públicos, demonstrando que condições de analfabetismo podem ser consideradas como marginalizantes. 
As pesquisas que se dedicam ao estudo da educação de jovens e adultos, além de outros aspectos, também buscam a caracterização do processo de aprendizagem e as representações estabelecidas pelos sujeitos envolvidos nesse segmento de ensino e têm revelado singularidades no desenvolvimento educacional da EJA. Com o intuito de conhecer o ponto de vista dos estudantes a respeito da aprendizagem em EJA e as relações com os professores, Camargo e Martinelli (2006) investigaram as percepções de alunos da EJA, que cursavam o nível de ensino fundamental sobre o processo ensino-aprendizagem.

As pesquisadoras entrevistaram 50 estudantes, sendo 20 do sexo masculino e 30 do feminino, com idades entre 14 e 80 anos, que frequentavam escolas de ensino fundamental $\left(1^{a}\right.$. a $4^{a}$. séries) de uma cidade do estado de São Paulo. $O$ instrumento utilizado foi uma entrevista semiestruturada composta por dois eixos principais: aspectos pessoais do aluno e do professor e aspectos relativos ao processo de ensino-aprendizagem. Os resultados revelaram que a relação afetiva que se estabelece entre professor e aluno na EJA influenciam, em grande medida, a análise e o julgamento que os estudantes fazem sobre o trabalho do professor. Outro resultado relevante diz respeito ao desempenho do aluno que pode ser atribuído ao esforço individual ou à vontade de aprender.

Na tentativa de melhor compreender o processo de aprendizagem na EJA, o trabalho de Laffin (2007) buscou descrever particularidades do processo educativo de jovens e adultos e identificar, na visão do professor, a relação dos estudantes com os saberes escolares, o papel mediador do professor na organização do trabalho pedagógico e na reciprocidade e acolhimento pelos alunos de suas ações intencionais frente ao processo ensino-aprendizagem. Para o desenvolvimento da pesquisa, propôs a análise do trabalho de 23 professores de uma rede de ensino municipal no estado de Santa Catarina e o exame das práticas pedagógicas dos participantes por meio de depoimentos.

A autora concluiu, ao final do estudo, que os professores entrevistados determinam as suas práticas e mediações pedagógicas durante o desenvolvimento do trabalho em sala de aula e nas relações com os alunos. Para a autora, essas práticas constituem a formação do profissional docente e determinam um estatuto próprio de ensino-aprendizagem em EJA. Considera ainda que tais práticas podem contribuir para novos estudos no campo da pesquisa educacional e discute a possibilidade de se repensar a formação de docentes 
em nível superior para que contemple as necessidades específicas do ensino de jovens e adultos.

Naiff e Naiff (2008) tiveram como objetivo identificar as representações sociais de alunos de um programa de EJA, no estado do Rio de Janeiro. A metodologia de pesquisa empregou uma entrevista com 247 estudantes sobre os motivos que os levaram a abandonar os estudos e, depois, retornar a estudar em programa de EJA. Outra técnica utilizada foi uma tarefa de evocação livre com o termo indutor "estudar". Na tarefa de evocação livre foi solicitado aos participantes que dissessem palavras que thes vinham à lembrança a partir do tema indutor.

As conclusões do estudo apontaram que a representação social sobre "estudar" contém elementos relacionados, principalmente, à garantia de renda e ao mercado de trabalho. Demonstrou também que os principais motivos apresentados pelos estudantes tratavam da exigência do mercado de trabatho por escolaridade mais elevada dos trabalhadores. $\bigcirc$ mesmo motivo foi apresentado como motivação para evasão escolar e também para a volta aos estudos. Sobre esses resultados, os autores discutem a necessidade de valorizar as representações sociais positivas dos alunos sobre a escola, mas que,

112 ao mesmo tempo, atendam ao desafio de tornar os saberes escolares mais compatíveis com a realidade ocupacional dos jovens e adultos.

Destacando o problema do abandono dos cursos pelos adultos e a motivação como aspecto da aprendizagem, o estudo de Kleiman (2001) afirmou, por meio de dados obtidos em entrevistas e depoimentos dos alunos, em um estudo etnográfico, que a motivação individual é bastante alta para o adulto que retorna aos estudos, mas que, mesmo assim, há desistências no percurso educacional de EJA. Nesse contexto, a autora define que os incentivos externos e sociais devam ser pesquisados e que muitos fatores como as práticas discursivas no uso da escrita, a identidade institucional do aluno, a descrição dos contextos das salas de aula, as relações de poder de classes, as diferenças dos grupos étnicos e de gêneros, devem ser considerados quando se trata da busca de soluções de evasão dos programas de EJA. $\bigcirc$ estudo discorre ainda sobre a necessidade de se desenvolverem pesquisas acadêmicas com vistas a uma interface entre essas questões e os programas de ensino da EJA.

Também abordando o contexto motivacional, na aprendizagem de estudantes de EJA, Caliatto e Martinelli (2009) realizaram um estudo com o 
objetivo de verificar a autoeficácia de alunos da Educação de Jovens e Adultos, do segundo ciclo do Ensino Fundamental e do Ensino Médio. $O$ instrumento utilizado para a coleta de dados foi uma escala que avaliou a percepção do estudante sobre o quanto se sente capaz de desempenhar uma série de situações relativas às atividades propostas pela escola.

Os resultados revelaram que os participantes da amostra se avaliaram suficientemente capazes ou muito capazes para lidar com as situações escolares, revelando níveis positivos de percepção de autoeficácia acadêmica. Discutiu-se que, tendo o público investigado retornado à escolarização tardiamente ou fora da idade própria, os resultados de elevada autoeficácia podem ser reveladores de uma disposição desses estudantes para enfrentarem os novos desafios presentes na idade adulta, dentre eles, a própria questão da escolarização tardia.

Os estudos anteriormente apresentados e suas constatações reiteram o pensamento de Freire (1975), que se dedicou à instrução e à criação de programas de ensino de alunos jovens e adultos, o qual afirmava que a aprendizagem é repleta de significados, crenças e representações sobre si, sobre os outros e sobre o mundo. Assim, a aprendizagem sendo construída pelo próprio sujeito torna a educação uma possibilidade de superação da consciência ingênua para a consciência crítica, da construção de um cidadão pleno e de um mundo mais humano. Para Freire (1991), é por meio da educação que se instrumentaliza o indivíduo para aquisição do conhecimento e de habilidades, que levam à compreensão das situações experimentadas na vida e possibilita ao indivíduo mobilizar ações individuais e coletivas, que consequentemente proporcionam a transformação da realidade.

Com vistas a contribuir para a compreensão do processo ensino-aprendizagem na educação de jovens e adultos, considerando a trajetória escolar dos estudantes e a percepção de autoeficácia, o objetivo principal da pesquisa foi o levantamento de características dos estudantes inseridos no sistema de ensino de EJA e daqueles que evadiram. Essa questão foi levantada devido à constatação de que, muitos alunos ingressantes ao curso de EJA desistem e regressam ao curso várias vezes, no intuito de concluí-lo. Acredita-se que - levantamento de características do público de EJA, em suas relações com aprendizagem e a evasão escolar, possa subsidiar conhecimentos importantes para a definição de um status próprio do segmento, com vistas à definição de 
práticas pedagógicas, políticas de desenvolvimento educacional e de novas pesquisas na área.

Especificamente, foi proposto verificar percepções de crenças de autoeficácia acadêmica de estudantes e ex-estudantes de EJA a partir de questões voltadas à trajetória escolar. Uma análise qualitativa das respostas foi realizada a fim de identificar e descrever os aspectos relativos às crenças de autoeficácia e que podem levar estudantes jovens e adultos a desempenharem comportamentos de persistência na conclusão do curso. Para tanto, adotaram-se como embasamento a Teoria Social Cognitiva e os estudos que envolvem a crença de autoeficácia (BANDURA, 1997) e que diz respeito à crença do indivíduo nas próprias capacidades de executar ações com o intuito de atingir um resultado, e mais especificamente, a autoeficácia acadêmica que está ligada ao esforço, à persistência e à perseverança em atividades relacionadas ao contexto escolar.

\section{Método}

114 Participantes

Os participantes da pesquisa foram 108 estudantes e ex-estudantes da Educação de Jovens e Adultos (EJA), mais especificamente alunos de ensino fundamental, segundo ciclo e ensino médio, que foram classificados em dois grupos. $\bigcirc$ primeiro grupo foi composto por 57 estudantes $152,77 \%$ da amostra) com idade média de 37,6 anos, sendo 28 do sexo feminino e 29 do sexo masculino. $\bigcirc$ segundo grupo foi formado por 51 ex-estudantes 147,22 \%) com idade média de 36,4 anos, sendo 20 do sexo feminino e 31 do sexo masculino. Foram considerados como estudantes (Grupo 1) os participantes devidamente matriculados e que frequentavam as aulas. A amostra considerada como do grupo de ex-estudantes (Grupo 2) foi composta pelos indivíduos que efetivaram a matrícula, mas que não deram prosseguimento ao curso, sendo considerados como estudantes evadidos. 
Quadro 1

Nível de ensino dos participantes

\begin{tabular}{|c|c|c|c|c|}
\hline \multirow{2}{*}{ Participantes } & \multicolumn{3}{|c|}{ Nível de ensino em EJA } & Total \\
\cline { 2 - 5 } & Fundamental & Médio & Não informado & \\
\hline Estudantes & 30 & 27 & - & 57 \\
\hline Ex-estudantes & 24 & 25 & 02 & 51 \\
\hline
\end{tabular}

Instrumentos

Instrumento de coleta de dados foi um questionário estruturado para ser respondido de forma dissertativa, sendo que as perguntas abordaram sobre o passado escolar do participante, o momento atual e sobre as expectativas de completar os estudos. $\bigcirc$ instrumento buscou ainda investigar aspectos relativos à percepção de autoeficácia acadêmica.

Procedimentos éticos

Previamente à realização da coleta de dados, o projeto de pesquisa e o termo de consentimento livre e esclarecido foram submetidos ao Comitê de Ética em Pesquisa da Universidade de Campinas (UNICAMP). A documentação foi admitida sem restrições sob o Parecer CEP n 342/2008, em 27 de maio de 2008, e seguiram-se as providências para realização do estudo.

Procedimento de coleta de dados

Com as autorizações e o consentimento livre e esclarecido da amostra, a coleta de dados foi realizada com os estudantes, presentes em sala de aula. A coleta estendeu-se por três dias consecutivos, nos períodos matutino, vespertino e noturno.

A coleta de dados com os participantes que não estavam frequentando o curso seguiu outro procedimento. Os indivíduos eram contatados por telefone e, posteriormente, procurados em suas residências para 
esclarecimentos sobre a pesquisa e sobre a forma de participação. As residências localizavam-se em diferentes bairros da cidade, escolhidos pela acessibilidade, sendo que foram visitados estudantes de bairros centrais e de periferia.

Os indivíduos, receptivos à proposta de participar da pesquisa, respondiam aos instrumentos no momento da visita, mas por alguns motivos apresentados naquele momento, alguns protocolos foram deixados nas residências e devolvidos, posteriormente, à pesquisadora. Foram visitadas, aproximadamente, 150 residências, no período de sete meses o que resultou em 51 protocolos possíveis de ser aproveitados na pesquisa.

\section{Resultados e discussão}

As respostas do questionário semidirigido foram categorizadas, conforme sugere Bardin (2008), e seguiram três fases: pré-análise, análise do material e tratamento dos resultados. A pré-análise foi realizada por meio da exploração do material, sendo que todas as respostas foram separadas buscando-se sinônimos, expressões com o mesmo sentido e 116 padrões nos conteúdos das respostas. A análise do material, que se iniciou pela organização das informações colhidas e a sintetização dos dados, possibilitou a categorização das respostas e a indicação da porcentagem das mesmas com o intuito de proceder à interpretação e à análise dos resultados. Os dados do questionário semidirigido, e relativos à percepção de autoeficácia, foram discutidos à luz da Teoria Social Cognitiva, mais especificamente sob os conceitos da teoria de autoeficácia (BANDURA, 1997) e com base na literatura da área.

\section{Tabela 1}

Frequencia das desistências

\begin{tabular}{ccccc}
\hline Respostas & Grupo 1 & $\%$ & Grupo 2 & $\%$ \\
\hline Nunca desistiram & 48 & 84,2 & - & - \\
Uma ou duas vezes & 07 & 12,3 & 45 & 88,2 \\
Três ou quatro vezes & 02 & 3,5 & - & - \\
Cinco vezes ou mais & - & - & 06 & 11,8 \\
Total de respostas & 57 & 100 & 51 & 100 \\
\hline
\end{tabular}


Considerando a questão relativa à evasão entre os estudantes, os resultados demonstram que a maioria nunca desistiu, ou que estão estudando desde que efetuaram matrícula, e apenas 15,8\% já se evadiram da EJA pelo menos uma vez. Dentre os ex-estudantes, todos estavam fora do sistema de ensino e os dados revelaram que a frequência com que desistiram do curso é marcante em relação ao primeiro grupo. Demonstra-se por parte dos ex-estudantes a dificuldade em levar a cabo a finalização do curso, mas, por outro lado, certa persistência, ao se matricularem novamente. Os motivos mais apontados para essa desistência do curso de EJA podem ser visualizados na Tabela 2.

Tabela 2

Sobre os motivos de desistência do curso de EJA

\begin{tabular}{ccccc}
\hline Respostas & Grupo 1 & $\%$ & Grupo 2 & $\%$ \\
\hline O horário do trabalho & 04 & 28,6 & 12 & 23,1 \\
$\begin{array}{c}\text { Deixou de estudar para } \\
\text { trabalhar }\end{array}$ & 04 & 28,6 & 08 & 15,4 \\
$\begin{array}{c}\text { Cansaço do trabalho ou } \\
\text { morava longe da escola }\end{array}$ & 02 & 14,3 & 07 & 13,5 \\
Motivos pessoais & 02 & 14,3 & 05 & 9,6 \\
Dificuldades no curso & 01 & 7,1 & 03 & 5,8 \\
Problemas de saúde & - & - & 03 & 5,8 \\
Não revelou & 01 & 7,1 & 14 & 26,9 \\
Total de respostas & 14 & 100 & 52 & 100 \\
\hline
\end{tabular}

Nas duas amostras de participantes, o trabalho foi o motivo mais apontado para o abandono da escola. Embora o curso de EJA fosse oferecido nos horários matutino, vespertino e noturno, no local onde foi realizada a 
pesquisa, as categorias mais frequentes foram: $\bigcirc$ horário do trabalho; Deixou de estudar para trabalhar; Cansaço do trabalho ou morava longe da escola. Destaca-se a palavra "cansaço" que foi interpretada como motivo relacionado ao "trabalho", pois descrevia que os indivíduos não se sentiam aptos a enfrentar uma jornada dupla de esforços e desenvolver estudos na escola, além de trabalhar. Motivos pessoais, como cuidar dos filhos e a falta de apoio familiar, foram apontados como a quarta categoria de respostas mais frequente para ambos os grupos pesquisados.

As respostas confirmam que os estudantes adultos enfrentam responsabilidades que nem sempre estão presentes quando se é estudante na chamada "época adequada aos estudos". Por meio dessas constatações, infere-se que são singularidades do público de EJA, que devem ser consideradas quando se articulam práticas pedagógicas e políticas de educação para essa modalidade. Isso está de acordo com trabalhos desenvolvidos na área de EJA como em Costa (2003), Laffin (2007) e Oliveira (2010) que reiteram que há inadequações de propostas na ação educativa desse público, sejam elas de linguagem, de abordagem metodológica ou de conteúdo, mas que podem ser superadas com a adoção de modos diferentes de transformação dos saberes

118 da cultura hegemônica para saberes mais próximos da cultura popular, que valorizem as histórias de vida, os interesses e os saberes dos estudantes.

De acordo com o INAF (2009), o Brasil sempre enfrentou o problema do analfabetismo, pleno ou funcional, entre jovens e adultos. Esse fato tem gerado a marginalização dessas pessoas de práticas socioculturais, uma vez que a falta de escolarização mínima é considerada de fundamental importância no desenvolvimento do indivíduo e como forma de enfrentar as demandas cotidianas e seguir aprendendo ao longo da vida. $\bigcirc$ fato de os estudantes abandonarem os estudos, em alguns momentos da trajetória educacional, influencia não só suas vidas pessoais, mas também interfere no contexto social. Assim, considerou-se importante investigar os motivos e em que época da trajetória escolar, a amostra analisada havia abandonado a instituição escolar, pela primeira vez. Esses dados encontram-se nas Tabelas 3 e 4. 
Tabela 3

Idade em que os participantes evadiram da escola regular

\begin{tabular}{ccccc}
\hline Idade & Grupo 1 & $\%$ & Grupo 2 & $\%$ \\
\hline Entre 07 e 10 anos & 06 & 10,5 & 04 & 7,8 \\
Entre 11 e 15 anos & 28 & 49,1 & 23 & 45,2 \\
Entre 16 e 18 anos & 09 & 15,8 & 12 & 23,5 \\
Acima de 18 & 09 & 15,8 & 06 & 11,8 \\
Migrou para EJA & 02 & 3,5 & - & - \\
Só frequentou EJA & - & - & 02 & 3,9 \\
Não lembra & 03 & 5,3 & 04 & 7,8 \\
Total de respostas & 57 & 100 & 51 & 100 \\
\hline
\end{tabular}

Os dados apresentados na Tabela 3 revelam que tanto os estudantes como os ex-estudantes evadiram da escola regular numa faixa etária semelhante, entre 11 e 15 anos, sendo essa a faixa de maior incidência de respostas. Logo após, a faixa etária mais apontada foi entre 16 e 18 anos de idade o que demonstra que, na amostra, houve maior evasão na faixa etária de jovens do que de crianças.

Esses dados eram esperados, pois, esses estudantes que buscavam retornar para EJA nos níveis de ensino Fundamental 2 e ensino Médio. Por outro lado, um grupo de alunos deixou a escola regular com idades entre 7 e 10 anos, faixa etária que corresponde ao nível de ensino fundamental $111^{\circ}$ ao $5^{\circ}$ ano das séries atuais). Considerando esse dado, pode-se constatar que a vida escolar de alguns estudantes se deu, em maior parte, nas salas de EJA. Para esses indivíduos, supõe-se que as dificuldades possam ter sido ainda maiores, pois tiveram que aprender as primeiras letras e se alfabetizar enquanto jovens ou adultos para alcançarem os níveis mais elevados de ensino, o que pode ser um dos motivos das desistências frequentes ao longo da trajetória escolar. 


\section{Tabela 4}

Motivos de evasão da escola regular

\begin{tabular}{ccccc}
\hline Respostas & Grupo 1 & $\%$ & Grupo 2 & $\%$ \\
\hline $\begin{array}{c}\text { Para trabalhar e ajudar a } \\
\text { família }\end{array}$ & 30 & 8,4 & 31 & 59,6 \\
$\begin{array}{c}\text { Motivos Pessoais (Desânimo, } \\
\text { interesse) }\end{array}$ & 06 & 7 & 06 & 11,5 \\
$\begin{array}{c}\text { Morava onde não tinha } \\
\text { escola }\end{array}$ & 07 & 1,3 & 03 & 5,8 \\
$\begin{array}{c}\text { Mudança abrupta de vida } \\
\text { Casamento e/ou gravidez }\end{array}$ & 04 & 5 & - & - \\
Falta de incentivo da família & 02 & 2 & 04 & 7,7 \\
Concluiu o fundamental e & - & 2 & 01 & 1,9 \\
parou & 01 & 6 & - & - \\
Sempre estudou em EJA & 10 & 6,1 & 05 & 9,6 \\
Em branco ou não se lembra & 62 & 100 & 52 & 100 \\
Total de respostas & 62 & - & 02 & - \\
\hline
\end{tabular}

principal motivo de evasão da escola regular, revelado pelos participantes, relacionou-se à necessidade de trabalhar para ajudar a família. Considerando tais motivos e os percentuais relativos à idade de evasão 111 e 15 anos), entende-se que se tratava de famílias de baixo poder socioeconômico. Motivos como morar longe da escola; A mudança abrupta na rotina da família; Casamento e ou gravidez; Falta de incentivo de membros da família, podem ser considerados de ordem extrínseca aos estudantes ou como fator de imposição externa.

Pode-se constatar que as dificuldades impostas pelo meio social, desde muito cedo, interferem na vida dos indivíduos e nas condições de acesso e evasão escolar. $\bigcirc$ trabalho de Naiff e Naiff (2008) já havia apontado a dimensão social do trabalho como principal motivo pelo qual os alunos jovens e adultos abandonaram a escola e também apontou o mesmo motivo quanto decidem retomar os estudos. 
No grupo de ex-estudantes, o segundo motivo mais frequente foi de ordem pessoal, pois declararam que desistiram dos estudos, por desânimo, falta de interesse ou falta de consciência sobre os estudos e a escola. $\bigcirc$ grupo de ex-estudantes foi o que mais inferiu motivos de ordem intrínseca ou de escotha do próprio indivíduo para evadir da escola. Caberia uma investigação sobre essa singularidade do grupo procurando relacionar a aparente dificuldade em se manter frequentando a escola e a motivação intrínseca para o estudo.

Os dados do presente estudo também revelaram diferentes motivações para o abandono da escola pelos estudantes, seja na época certa quando deveriam frequentar o ensino fundamental, seja na trajetória em EJA. A motivação mais frequentemente apontada se relacionou ao trabalho. Essas análises podem conduzir para a necessidade de maior reflexão e pesquisa sobre as causas de abandono que são externas ao indivíduo. Da mesma forma que se buscou investigar os motivos para a evasão escolar também foi possível conhecer as motivações para o retorno aos estudos e adesão à EJA. Os resultados dessas análises podem ser conferidos nas tabelas abaixo.

Tabela 5

Idade em que os participantes retornaram aos estudos

\begin{tabular}{ccccc}
\hline Idades & Grupo 1 & $\%$ & Grupo 2 & $\%$ \\
\hline Entre 15 e 19 & 05 & 8,8 & 08 & 15,7 \\
Entre 20 e 29 & 14 & 24,5 & 17 & 33,4 \\
Entre 30 e 39 & 15 & 26,3 & 09 & 17,6 \\
Entre 40 e 49 & 12 & 21,1 & 09 & 17,6 \\
Acima de 50 & 03 & 5,3 & 02 & 3,9 \\
Não sabe ou sempre estudou & 08 & 14 & 06 & 11,8 \\
na EJA & 57 & 100 & 51 & 100 \\
Total de respostas & 01 & 6 & - & - \\
Sempre estudou em EJA & 10 & 6,1 & 05 & 9,6 \\
Em branco ou não se lembra & 62 & 100 & 52 & 100 \\
Total de respostas & 62
\end{tabular}


Ao se levantar a idade em que os grupos de participantes retornaram à escola, verificou-se que os estudantes que estavam cursando o ensino de EJA retornaram entre 30 e 39 anos e os ex-estudantes entre 20 e 29 anos. De acordo com as categorias de respostas, sabe-se que a maioria dos indivíduos regressou à escola em idade adulta, e que, possivelmente, o retorno foi motivado pela necessidade de participação no mercado de trabalho, de definir carreiras ou por possuir famílias com filhos e dependentes. Observou-se ainda que o grupo de estudantes retornou à escola com idade mais avançada e, considerando que nesse grupo há menor índice de desistências, infere-se que a maior maturidade possa estar relacionada à perseverança para terminar o curso, porém a amostra limitada desse estudo não permite conclusões nesse sentido.

\section{Tabela 6}

Sobre os motivos que levaram os participantes a optarem pela EJA

\begin{tabular}{ccccc}
\hline Idades & Grupo 1 & $\%$ & Grupo 2 & $\%$ \\
\hline $\begin{array}{c}\text { Crença em vantagens do } \\
\text { curso de EJA sobre o ensino } \\
\text { regular. }\end{array}$ & 14 & 21,9 & 08 & 14,3 \\
$\begin{array}{c}\text { Imposição do emprego } \\
\text { Ascender na profissão ou dar } \\
\text { continuidade aos estudos. }\end{array}$ & 04 & 6,2 & 11 & 19,6 \\
$\quad$ Para ter certificado & 08 & 12,5 & 09 & 16,1 \\
Melhorar a qualidade de & 05 & 7,8 & 06 & 10,7 \\
vida. & 06 & 9,4 & 02 & 3,6 \\
Vontade ou gosto pelo estudo & 04 & 6,2 & 03 & 5,3 \\
Obter conhecimentos & 11 & 17,2 & 09 & 16,1 \\
$\quad$ Não sabe & 64 & 100 & 56 & 100 \\
\hline Total de respostas & & & & 14,3 \\
\hline
\end{tabular}

No que diz respeito às razões para se optar pelo curso de EJA, em comparação ao sistema regular de ensino, a maior incidência de respostas, no grupo de estudantes, esteve relacionada às vantagens oferecidas pelo curso 
tais como, o aproveitamento do tempo e o oferecimento do curso em vários horários. Para os ex-estudantes, porém, a resposta mais presente relacionou-se a uma necessidade imposta ao indivíduo pelo mercado de trabalho, como quando é exigida a conclusão de um nível de ensino para permanência do trabalhador na função ou no emprego. Esse dado parece, no entanto, se contrapor ao perfil desses alunos que foram selecionados pelo fato de desistirem mais vezes do curso. Infere-se, assim, que a imposição para o estudo tem sido um motivo fraco para garantir a permanência desses trabalhadores na escola.

Por outro lado, algumas respostas evidenciadas tais como, ascender profissionalmente e na escola, obter o certificado, melhorar a qualidade de vida, ter vontade de estudar, gostar de estudar e obter conhecimentos revelam uma conotação positiva a respeito da percepção dos participantes sobre as possibilidades que a escola ou os estudos oferecem às suas vidas e legitimam a busca e o retorno à escola, apesar de repetidas desistências e abandonos.

Sob o ponto de vista de que os indivíduos procuram a EJA por motivos intrínsecos, buscou-se uma análise das crenças de autoeficácia acadêmica, uma vez que a estas têm sido atribuída uma maior persistência e a perseverança em atividades relacionadas ao contexto escolar. Com o intuito de verificar sobre a presença de crenças de autoeficácia, como elemento presente na percepção dos estudantes em relação ao ensino escolar, perguntou-se que elementos seriam importantes para se obter a melhoria da aprendizagem.

\section{Tabela 7}

Sobre o que é importante para o aprendizado do estudante de EJA

\begin{tabular}{|c|c|c|c|c|}
\hline Categorias de respostas & Grupo 1 & $\%$ & Grupo 2 & $\%$ \\
\hline $\begin{array}{c}\text { Motivação pessoal (determinação, } \\
\text { empenho, objetivos, perseverança, } \\
\text { dedicação, gostar de estudar, saber } \\
\text { que é capaz) }\end{array}$ & 32 & 35,1 & 06 & 10,3 \\
\hline $\begin{array}{l}\text { Ações de estudo em casa (rever, ar- } \\
\text { rumar tempo de estudar, ler, pesquisar) }\end{array}$ & 16 & 17,6 & 16 & 27,6 \\
\hline $\begin{array}{c}\text { Ações do Professor (resumos, ter um } \\
\text { bom professor) }\end{array}$ & 14 & 15,4 & 08 & 13,8 \\
\hline
\end{tabular}


Ações de estudo na escola (prestar atenção na aula, fazer perguntas, frequentar)

Não quis ou não soube opinar

Ações políticas (melhoria da qualidade de ensino, do prédio escolar, ter materiais)

Acha que não precisa melhorar nada.

04

4,4

04

6,9

Outros tipos de respostas

A categoria de resposta mais apontada pelo grupo de estudantes denotou motivações subjetivas e intrínsecas ao indivíduo, por isso foi nomeada como motivação pessoal. Pode-se articular que são crenças do indivíduo sobre a necessidade de motivação positiva em relação ao aprender, como ter determinação, empenho, perseverança, dedicação, gostar de estudar, ter objetivos, saber que é capaz. Já para o grupo de ex-estudantes, a categoria mais apontada relacionou ações práticas para melhoria da aprendizagem individual como estudar em casa ou rever a matéria, ter tempo de estudar em casa, ler e pesquisar, sendo que a mesma categoria também foi a segunda mais apresentada pelo grupo de estudantes.

Outras respostas que demonstraram a persistência que o estudante deve ter para um bom desempenho na aprendizagem foram expressas, pelos dois grupos, na categoria Ações de estudo na escola, que envolveu respostas como prestar atenção na aula, fazer perguntas e frequentar as aulas. As respostas que determinaram tais categorias foram comparadas a percepções de autoeficácia acadêmica, pois as afirmações remetem a necessidade do indivíduo em mobilizar, por si, as condições motivacionais e práticas para que a própria aprendizagem ocorra.

Bandura (1997) afirmou que os indivíduos necessitam de uma firme confiança em sua eficácia para organizar e manter um comportamento, como se a confiança na própria capacidade fosse base para a ação. Além disso, a autoeficácia é um processo cognitivo referente à confiança do indivíduo em sua habilidade para regular a própria motivação, os pensamentos e o estado 
emocional, que, consequentemente, interferem no meio social. No entanto é importante reafirmar que o questionário semiestruturado não pretendia verificar o quanto os participantes se sentem capazes de executar ações para melhoria do aprendizado, e, portanto não teve propósito de mensurar a autoeficácia acadêmica. Salienta-se que outros estudos voltados à autoeficácia acadêmica de estudantes da EJA possam contribuir com uma base de conhecimentos mais sólidos sobre os fatores intervenientes no aprendizado desse segmento de estudantes.

As categorias de respostas nomeadas ações do professor e ações políticas representou, para os participantes, a necessidade de condições socioambientais, externas a sua motivação pessoal, para que pudessem aprender os conteúdos escolares. De maneira geral, e comparando-se os percentuais das categorias de respostas, nota-se uma tendência dos estudantes a apontarem para si a maior responsabilidade pela aquisição de novas aprendizagens na escola.

\section{Tabela 8}

Crença do estudante sobre a própria capacidade para obter boas notas e boa aprendizagem

\begin{tabular}{ccccc}
\hline Tipos de respostas & Grupo 1 & $\%$ & Grupo 2 & $\%$ \\
\hline Positivas & 44 & 77,2 & 34 & 66,7 \\
Negativas & 01 & 1,7 & 02 & 3,9 \\
Incerteza & 03 & 5,3 & 04 & 7,8 \\
Em branco & 09 & 15,8 & 11 & 21,6 \\
Total de respostas & 57 & 100 & 51 & 100 \\
\hline
\end{tabular}

A questão sobre a crença na própria capacidade para obter notas altas procurou levantar crenças (positivas ou negativas) que o participante apresentava em relação a sua obtenção de sucesso escolar, visto que as notas em provas representam o aproveitamento dos estudantes em relação aos estudos e à escola. As respostas consideradas como crenças positivas tratavam de afirmativas da possibilidade de obtenção de boas notas na maioria das disciplinas ou matérias e as crenças negativas, o oposto. 
Analisando-se os dados expressos na tabela, os participantes revelaram acreditar que poderiam ter boas notas e consequentemente sucesso escolar. Para as respostas negativas, observa-se que, em ambos os grupos, não houve incidência expressiva de respostas. Algumas respostas foram categorizadas e nomeadas como incerteza uma vez que os estudantes não asseguravam de forma positiva ou negativa sua confiança em tirar boas notas. Destaca-se que os participantes tiveram mais incertezas do que respostas negativas.

A expressão ser capaz de tirar boas notas na pergunta do questionário quis provocar uma percepção de eficácia para obtenção de boas notas. Assim, esses resultados puderem ser considerados coerentes com uma boa percepção da crença de autoeficácia, uma vez que, aparentemente, eles não se veem, na maioria, incapazes de obter boas notas. Desse modo, infere-se que as crenças expressas, nesses resultados, sustentam as várias tentativas dos alunos em buscar o ensino de EJA, por terem na percepção de que são capazes de ser bem-sucedidos, quando, efetivamente, levarem a cabo os estudos.

Essas análises consideram a perspectiva teórica apontada por Bandura (1997) que afirmou que as crenças de autoeficácia podem influenciar escolhas, aspirações e a quantidade de esforço para executar uma tarefa.

126 Bzuneck (2004) afirmou, também, que, no contexto acadêmico, um aluno motiva-se a se envolver nas atividades de aprendizagem caso acredite que, com os seus conhecimentos, talentos e habilidades, poderá dominar novos conteúdos, melhorar suas habilidades, entre outras possibilidades de domínio escolar. Considera ainda que o aluno motivado será capaz de selecionar atividades e estratégias de ação que, segundo prevê, poderão ser executadas.

Ainda com o intuito de conhecer mais sobre esses estudantes e sobre sua trajetória escolar passada, perguntou-se o que os participantes poderiam declarar sobre suas vitórias e derrotas durante o percurso escolar. As análises das respostas estão expressas na tabela a seguir.

\section{Tabela 9}

Sobre as conquistas ou vitórias na trajetória escolar

\begin{tabular}{ccccc}
\hline Categorias de respostas & Grupo 1 & $\%$ & Grupo 2 & $\%$ \\
\hline $\begin{array}{c}\text { Ter sido bom aluno (ser esforçado, tirar } \\
\text { boas notas) }\end{array}$ & 17 & 31,5 & 5 & 12,5 \\
& & & & \\
\hline
\end{tabular}


Retomada dos estudos: ter iniciativa, coragem.

Conquistas no âmbito profissional e familiar.

Aprendizado (obter novos conhecimentos)

Aspectos sociais (ser bem recebido na escola, fazer amizades, ter atenção dos professores).

Em branco

Total de respostas

10

$$
7
$$

2

2

3,7

1

2,5

10

18,5

9

22,5

$54 \quad 100$

40

100

A questão sobre as vitórias na trajetória escolar buscou identificar se estudantes e ex-estudantes reconheciam, de forma positiva, as vivências escolares. A categoria de respostas mais frequente entre os estudantes foi ter sido um bom aluno na escola, ser esforçado e dedicado ou ainda um aluno com boas notas que sugeriram vivências passadas ou atuais sobre a escolarização. A segunda categoria mais frequente foi ter retomado os estudos, que, para ex-estudantes, foi a categoria mais escolhida. Pode-se considerar que essas respostas dimensionaram a possibilidade de as vivências na escola serem consideradas conquistas e vitórias ligadas ao esforço e à dedicação pessoal.

Para o grupo de ex-estudantes ter a categoria de resposta em branco, como a segunda de maior frequência pode demonstrar dificuldade em reconhecer na escola situações positivas, de ganho, vitória ou sucesso uma vez que se encontram fora dela. Alguns participantes relacionaram a pergunta com aspectos pessoais e relataram como sucesso o fato de terem emprego, família e moradia, o que determinou a categoria Conquistas no âmbito profissional e familiar, que não era esperada para a questão.

As categorias de respostas Aprendizado e Aspectos Sociais, apontadas pelos participantes, como conquista ou vitórias, foram interpretadas como forma de valorização da função social da escola em transmitir conhecimentos e possibilitar trocas de experiências. Na tabela a seguir, encontram-se categorizadas as respostas dos estudantes o que consideram como fracassos e derrotas na trajetória escolar. 
Tabela 10

Sobre os fracassos ou derrotas na trajetória escolar

\begin{tabular}{ccccc}
\hline Categorias de respostas & Grupo 1 & $\%$ & Grupo 2 & $\%$ \\
\hline $\begin{array}{c}\text { Ter abandonado os estudos em al- } \\
\text { guma época. }\end{array}$ & 20 & 34,5 & 14 & 31,8 \\
$\begin{array}{c}\text { Dificuldades (para aprender, com a } \\
\text { escola ou com os professores, falta de } \\
\text { incentivo) }\end{array}$ & 10 & 17,2 & 11 & 25 \\
Falta de interesse pelos estudos & 09 & 15,6 & 5 & 11,4 \\
$\quad$ Não lembra & 07 & 12,1 & 2 & 4,5 \\
Dificuldades financeiras, trabalho ou & 02 & 3,4 & 3 & 6,8 \\
$\quad$ família & 10 & 17,2 & 9 & 20,5 \\
Não quis responder & 58 & 100 & 44 & 100 \\
Total de respostas & & & &
\end{tabular}

Para os participantes da pesquisa, o fato de haver deixado os estudos 128 em alguma época da vida foi considerado um fracasso ou derrota pessoal na trajetória escolar. Essa resposta foi condizente com a questão anterior que via o retorno à escola como uma vitória ou sucesso.

A segunda categoria de resposta mais apontada por ambos os grupos, como reconhecimento de fracasso escolar, demonstra que alunos adultos têm consciência das próprias dificuldades de aprendizagem, já que declaram sentirem-se fracassados quando não compreendem a explicação do professor, não aprendem algum conteúdo ou quando tiram notas baixas. A falta de interesse pelos estudos na juventude também foi declarada de forma expressiva como fracasso para estudantes e ex-estudantes, sendo a terceira categoria de respostas mais frequentes para ambos os grupos.

Nessa questão, os grupos se comportaram de forma bastante semethante quanto às frequências nas categorias de respostas. Uma parcela de participantes, ao responderem à questão, não mencionou conteúdos que apontassem qualquer visão sobre o fracasso escolar, por isso foi criada a categoria não declara nenhum fracasso, junto com outra resposta de que não se lembravam de fracassos ou derrotas. As respostas referentes aos aspectos pessoais, como perda de emprego, dificuldades familiares entre outras respostas 
singulares, citadas como respostas a essa questão, também foram categorizadas apesar de não responderem diretamente à questão.

\section{Considerações finais}

$\bigcirc$ presente trabalho partiu do pressuposto de que o público de EJA apresenta aspectos próprios e singularidades, como estudantes, e também em suas relações com a aprendizagem escolar, pelo fato de que retomam, tardiamente, os estudos. Essa premissa norteou o presente estudo que se propôs investigar esse público com o intuito de buscar informações que pudessem guiar novas propostas para a condução do processo ensino-aprendizagem junto a essa população. Os resultados das análises realizadas revelaram uma série de informações e características que serviram de base para as considerações que se tecem a seguir.

Nota-se que os estudantes de EJA são trabalhadores que apresentam a característica de competir no mercado de trabalho, mas com pouca instrução escolar, atuando como mão de obra em serviços braçais que demandam esforço físico, além do mental. Nesse contexto, dificilmente os indivíduos escoIheram a profissão por vocação, mas por necessidade de renda e os estudos escolares vêm como uma necessidade imposta pelo meio externo, conforme se verificou nas respostas em que os estudantes afirmam retomar os estudos por imposição do trabalho.

Todavia, apesar das dificuldades impostas e a pressão social para que o adulto volte a estudar, as respostas dos participantes da pesquisa também transmitiram percepção de boa motivação para os estudos, quando relataram a busca de melhoria da própria condição social, e dos aspectos do trabalho por meio das aprendizagens escolares. Essa motivação também pode ser sentida, de forma mais acentuada, quando se observa que estudantes e ex-estudantes apresentam motivos (gostar de estudar, sentir-se capaz) e ações práticas (rever o conteúdo em casa e frequentar as aulas) como elementos importantes para que o aprendizado ocorra.

Alguns dados induzem a afirmar que uma boa parte do público de EJA mantém características motivacionais importantes sobre as próprias capacidades de relacionar-se com a aprendizagem institucional, apesar de toda a dificuldade apontada pelos estudantes de EJA para frequentarem a escola, uma 
vez que permaneciam frequentando as aul as e persistiam para atingir o objetivo final que era a conclusão do curso.

Embora o grupo de ex-estudantes demonstrasse maior histórico de evasões durante a trajetória escolar, ainda apresentaram repetidas tentativas de retornar à escola e também apresentaram percepções de autoeficácia para tirar boas notas, caso estivessem cursando a EJA. Os grupos de estudantes e ex-estudantes, igualmente, revelaram motivação positiva sobre a escola e a aprendizagem como se observa nas respostas que apontaram a retomada dos estudos como vitória ou conquista dos participantes.

A proposição que se faz sobre esses resultados é a de que muitas variáveis podem estar envolvidas na desistência do curso ou na evasão escolar desses estudantes. Os motivos relacionados ao trabalho foram os mais apontados para a desistência e evasão escolar. Outras respostas demonstraram que os estudantes evadiram porque "não conseguiam conciliar o horário de trabalho com o da escola" e "depois de trabalhar o dia todo se sentiam cansados para ir à escola". Estabeleceu-se, por meio dessas afirmativas, conotação de que as dificuldades para o aluno de EJA retomar os estudos e persistir na frequência às aulas estão mais relacionadas a aspectos ambientais e sociais 130 do que pessoais.

Outro dado também demonstrou que os jovens e adultos têm presente em suas vidas as condições do trabalho e as relações estabelecidas por ele, quando apontam o trabalho como o maior incentivo para frequentarem a escola e obter o certificado de conclusão. Nesse contexto, não é possível ignorar que as escolas e mesmo os professores deveriam aliar os conteúdos disciplinares às realidades vividas, por seus alunos, no contexto laboral.

A proposta pode ser desenvolvida por meio da adequação dos temas de leitura, das produções de textos ou de situações-problema da Matemática que são utilizados nas aulas, por exemplo. Acredita-se que a familiaridade como os temas pode levar o aluno a desenvolver maior confiança em participar das aulas e executar as tarefas e, consequentemente, servir como incentivo para que o estudante desenvolva ações em prol da efetivação do curso até o fim.

Os resultados de percepção da autoeficácia na presente pesquisa permitem refletir sobre implicações pedagógicas ou proposições educacionais ao público de EJA. Considerando a importante relevância do papel da autoeficácia 
acadêmica para a motivação e ações dos estudantes, tanto nas atividades escolares, como em práticas que organizam e impulsionam o desempenho, torna-se evidente a necessidade de intervenção por parte do professor de EJA para cultivar e manter a autoeficácia dos estudantes. As intervenções devem promover situações de sucesso aos estudantes, de forma que as atividades propostas sejam desafiadoras, mas não sejam tão difíceis a ponto de não se conseguir realizá-las.

A condição de se realizar a tarefa com algum esforço melhora a percepção da capacidade individual e está de acordo com a principal fonte de autoeficácia que são as experiências de sucesso. (BANDURA, 1997). As intervenções podem ser relacionadas ao desenvolvimento da colaboração e da amizade em sala de aula em detrimento da competição escolar, uma vez que a teoria da autoeficácia aponta que as boas relações interpessoais estão relacionadas à boa percepção da autoeficácia e que a experiência vicariante, de observação dos pares, é uma fonte de aprendizagem e de autoeficácia. (BANDURA, 1993). Cabe à escola ser um ambiente estimulador da aprendizagem cooperativa, um lugar que privilegia a interação, o respeito às diferenças e a exposição das experiências pessoais como modelos de aprendizagem, além das estratégias propostas pelo professor.

As publicações sobre a mensuração da autoeficácia e da autoeficácia acadêmica têm-se proliferado amplamente, demonstrando grande interesse por parte dos pesquisadores em investigar a autoeficácia no âmbito escolar e educacional. Isso é muito positivo, visto que permite a constatação da força e da robustez do constructo relacionado aos processos de ensino e de aprendizagem. Por outro lado, pôde-se verificar uma lacuna de estudos da autoeficácia abordando o público de alunos da EJA, que são também pouco explorados quando se refere aos mecanismos de aprendizagem e motivação para aprender. Dada a importância da crença da autoeficácia para o contexto acadêmico e educacional, sugere-se que novos instrumentos e avaliações devam ser desenvolvidos para o atendimento à população de adultos na EJA.

Ao finalizar este texto, considera-se oportuno levantar alguns desafios enfrentados pela pesquisa realizada. A amostra deste estudo pode ser considerada reduzida para se obterem resultados conclusivos, porém a totalidade de alunos atendidos pelo EJA da localidade foi convidada a participar da pesquisa, havendo algumas desistências ou recusas. 
Apontam-se também limitações quanto ao instrumento utilizado, visto que as respostas de questões abertas revelaram ser um elemento dificultador para os participantes, que nem sempre revelavam, com clareza e coerência, suas ideias e, em algumas situações, se distanciavam do que havia sido perguntado. Posteriormente, também a categorização das respostas se tornou bastante complexa. Salienta-se, por fim, que as particularidades do público-alvo e os instrumentos utilizados conferem a este estudo um caráter exploratório, que pode ser considerado como um ponto de partida para futuras investigações.

\section{Referências}

BANDURA, Albert. Perceived self-efficacy in cognitive development and functioning. Educational Psychologist, Lawrence Erlbaum Associates, Inc., Mahwah, NJ, v. 28, n. 2, 117-148, 1993.

Self-efficacy: the exercise of control. New York: Freeman, 1997.

BARDIN, Laurence. Análise de conteúdo. 19 ed. Lisboa: Edições 70, 2008.

BOLETIM Informativo do Indicador de Alfabetismo Funcional - INAF, 2009. Instituto Paulo Montenegro. Disponível em: <http://www.ibope.com.br/ipm/ relatorios/relatorio _inaf_2009.pdf.> Acesso em: 03 jun. 2011.

BRASIL. Educação para jovens e adultos: ensino fundamental proposta curricular - $1^{\circ}$ segmento. RIBEIRO, Vera Maria Masagão (Coord.). São Paulo: Ação Educativa; Brasília: MEC, 2001.

Ministério da Educação e Cultura. Trabalhando com a educação de jovens e adultos: alunas e alunos da EJA. Brasília, 2006. Disponível em: < hitp://portal.mec.gov.br/ secad/arquivos/pdf/eja_caderno 1.pdf>. Acesso em: 22 jan. 2010.

BZUNECK, José Aloyseo. As crenças de auto-eficácia e o seu papel na motivação do aluno. In: BZUNECK, José Aloyseo; BORUCHOVITCH, Evely (Org.). Motivação do aluno: contribuições da psicologia contemporânea. Petrópolis: Vozes, 2004.

CALIATTO, Susana Gakyia; MARTINELLI, Selma de Cássia. Avaliação da Autoeficácia Acadêmica em Alunos da Educação de Jovens e Adultos. ETD - Educação Temática Digital, Campinas, v. 10, p. 187-203, out. 2009. (Número especial). Disponível em: < hitp:// www.brapci.ufpr.br/index.php>. Acesso em: 01 dez. 2011. 
CAMARGO, Poliana da Silva Almeida Santos; MARTINELLI, Selma de Cássia. Educação de Adultos: Percepções sobre o processo ensino aprendizagem. Psicologia Escolar e Educacional, Campinas, v. 10, n. 2, dez. 2006.

COSTA, Alexandre. Alfabetização de Jovens e Adultos e mudança social: uma abordagem discursiva para o fenômeno do analfabetismo. In: MAGALHÃES, Izabel; LEAL, Maria Cristina (Org.). Discurso, gênero e educação. Brasília: Plano Editora, 2003.

FREIRE, Paulo. Educação como prática da liberdade. 5. ed. Rio de Janeiro: Paz e Terra. 1975.

Pedagogia da esperança. São Paulo: Paz e Terra, 1991.

KLEIMAN, Angela Bustos. Programas de educação de jovens e adultos e pesquisa acadêmica: a contribuição dos estudos do letramento. Educação e Pesquisa, São Paulo, v. 27, n. 2, p. 267-281, jul./dez. 2001.

LAFFIN, Maria Hermínia Lage Fernandes. Reciprocidade e acolhimento na educação de jovens e adultos: ações intencionais na relação com o saber. Educar em Revista, Curitiba, n. 29, p. 101-119, jan./jun. 2007.

NAIFF, Luciene Alves Miguez; NAIFF, Denis Giovani Monteiro. Educação de jovens e adultos em uma análise psicossocial: representações e práticas sociais. Psicologia \& Sociedade, Belo Horizonte, v. 20, n. 3, p. 402-407, set./dez. 2008.

OLIVEIRA, Inês Barbosa de. As interfaces educação popular e EJA: exigências de formação para a prática com esses grupos sociais. Educação, Porto Alegre, v. 33, n. 2, p. 104-1 10, maio/ago. 2010.

STROMQUIST, Nelly. Convergência e divergência na conexão entre gênero e letramento: novos avanços. Educação e Pesquisa, São Paulo, v. 27, n. 2, p. 301-320, jul./dez. 2001.

Profa. Dra. Susana Gakyia Caliatto Universidade de Vale do Sapucaí UNIVAS | Pouso Alegre | Minas Gerais Faculdade de Filosofia Ciências e Letras Eugênio Pacelli | FaFiep Grupo de Estudo Educação, Ciência e Aprendizagem. E-mail | caliattosg@univas.edu.br 


Profa. Dra. Selma de Cássia Martinelli
Universidade Estadual de Campinas UNICAMP | Campinas | São Paulo
Faculdade de Educação
Grupo de Estudos e Pesquisa em Psicopedagogia | GEPESP
E-mail | selmacm@unicamp.br
Recebido 21 ago. 2013
Aceito 17 dez. 2013

